УДК 620.1

DOI https://doi.org/10.32838/2663-5941/2019.3-1/09

\begin{abstract}
Иценко А.И.
Институт проблем материаловедения имени И.Н. Францевича

Национальной академии наук Украины
\end{abstract}

\title{
Шевченко А.И.
}

Главная астрономическая обсерватория

Национальной академии наук Украины

\section{Богдан Г.А.}

Национальный технический университет Украины

«Киевский политехнический институт имени Игоря Сикорского»

\section{КОНТРОЛЬ ОДНОРОДНОСТИ РАСПРЕДЕЛЕНИЯ ПРОЧНОСТНЫХ ХАРАКТЕРИСТИК В МАТЕРИАЛАХ ИЗ НИТРИДА АЛЮМИНИЯ ПО РЕЗУЛЬТАТАМ АКУСТИЧЕСКИХ ИЗМЕРЕНИЙ}

В статье рассмотрены вопросы проведения интегральной оценки однородности распределения прочностных характеристик в порошковых материалах, изготовленных на основе нитрида алюминия, по результатам акустических измерений. Для определения акустических параметров материала был реализован ультразвуковой метод прохождения. В качестве основного информачионного параметра для исследований была использована скорость прохождения ультразвуковой волны в объекте контроля. По результатам экспериментальных исследований установлено, что в образиах присутствует разброс физико-механических характеристик (плотность, модуль упругости) в пределах 10\%. Такой разброс возник за счёт вариации физико-механических характеристик сырья, технологических параметров, условий прессования и разности температуры спекания.

Ключевые слова: ультразвук, неразрушающий контроль, скорость распространения, порошковые материаль, нитрид алюминия, технология изготовления.

Постановка проблемы и анализ последних исследований и публикаций. На сегодняшний день широкое распространение в различных областях промышленности получили материалы, изготовленные методами порошковой металлургии на основе нитрида алюминия (AIN) [1-6]. Нитрид алюминия - бинарное неорганическое химическое соединение алюминия с азотом, материал относится к структурам с ковалентными связями, имеющими гексагональную кристаллическую структуру типа вюрцита (рис. 1) [7].

Для создания композиционных материалов, работающих в экстремальных условиях, нитрид алюминия представляет интерес по целому ряду причин. Он отличается аномально высокой теплопроводностью. Монокристаллический $\mathrm{A} 1 \mathrm{~N}$ имеет теплопроводность около $350 \mathrm{BT} /($ м К), что сравнимо и даже превосходит теплопроводность меди. Наряду с этим нитрид алюминия обладает значительным удельным электросопротивлением $10^{13} \div 10^{14}[\mathrm{Oм} \cdot \mathrm{cm}]$, низким тангенсом угла диэлектрических потерь $(3 \div 12) \cdot 10^{-4}$. Прочность на изгиб керамики на основе нитрида алюминия находится на уровне 300 МПа. Нитрид алюминия обладает коррозионной стойкостью к воздействию расплавов многих металлов. Например, металлический алюминий не взаимодействует с нитридом алюминия до 1773 К. Такой комплекс свойств позволяет использовать материалы на основе нитрида алюминия в энергетике и металлургии для изготовле-

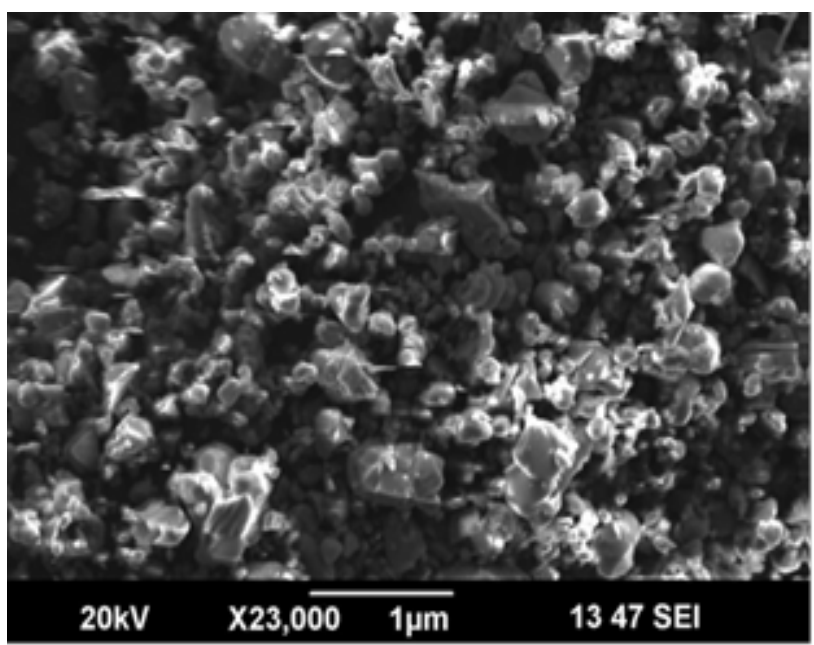

Рис. 1. Кристаллическая структура порошка нитрида алюминия 
ния испарительных элементов, сопел, фильтров и тиглей для разливки металлов, защиты электролизеров и электродов, в электронике и технике СВЧ вместо керамики из оксида бериллия [1-8].

Согласно существующим на сегодняшний день методикам оценку физико-механических характеристик порошковых материалов получают путём использования разрушающих метод контроля [9]. Главными недостатками таких методов является то, что они не дают интегральную оценку распределения исследуемых физико-механических параметров материала, требуют изготовления образцов определённой формы и приводят к их полному разрушению. Для обеспечения стабильности воспроизведения служебных характеристик изделий, изготовленных на основе AlN, необходимо контролировать распределение прочностных свойств (модуль упругости) как между образцами, так и в объёме отдельно взятого объекта. Для оценки реальных физико-механических характеристик объекта контроля (ОК) на всех этапах изготовления материала рационально использовать результаты измерений, полученных на основе акустических методов неразрушающего контроля [10-11].

Постановка задачи. В данной работе рассматривается возможность исследования оценки однородности распределения прочностных характеристик в объёме образца, изготовленного из $\mathrm{AlN}$, по результатам измерений скорости распространения ультразвуковой волны, а также степени повторяемости свойств между образцами одной и различных партий порошковых материалов, которые изготовлены по одной технологии.

Изложение основного материала исследования. Образцы были изготовлены в Институте проблем материаловедения им. И.Н. Францевича НАН Украины по следующей технологической схеме. Порошки нитрида алюминия смешивали с пластификатором (раствор каучука в бензине). Затем получали гранулы путём протирания пластифицированной массы через сито с ячейкой размером 4 мм. Гранулы засыпали в стальную прессформу и прессовали при удельном давлении 200 МПа. Спрессованные образцы спекали в высокотемпературной графитовой печи в среде азота при температуре спекания $1800 \div 1850^{\circ} \mathrm{C}$.

В качестве объекта контроля испытывались цилиндрические заготовки диаметром от 8 до 9 мм и высотой $12 \div 13$ мм. Их внешний вид представлен на рис. 2.

Прозвучивание ультразвуковой волной проводилось вдоль центральной оси цилиндра.

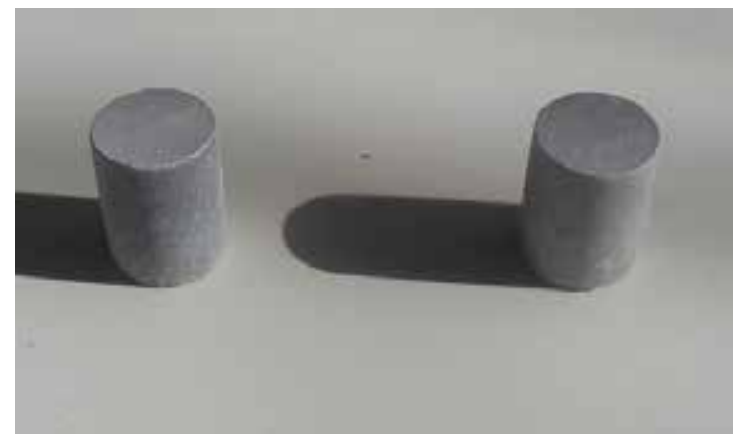

Рис. 2. Внешний вид ОК

Как известно, ультразвуковые методы неразрушающего контроля относятся к непрямым методам измерений. Искомый физико-механический параметр исследуемого материала находится по известным корреляционным или аналитическим зависимостям [12]. В качестве основного информационного параметра для наших исследований мы использовали скорость прохождения ультразвуковой волны в ОК. Скорость $(C, \mathrm{~m} / \mathrm{c})$ распространения ультразвуковой волны в ОК при использовании метода прохождения рассчитывается по формуле (1):

$$
C=\frac{h}{t-t_{0}},
$$

где $h$ - геометрическая база измерения (толщина изделия в точке измерения), м; $t$ - время прохождения ультразвукового импульса вдоль базы измерения, c; $t_{0}$ - систематическая временная поправка, с.

Для измерения времени прохождения $t$ и геометрических размеров базы прозвучивания $h$ была использована лабораторная установка, структурная схема которой показана на рис. 3 , исследования проводились на частоте 5 МГц. Принцип действия установки описан в работе [13].

Данная установка позволяет обеспечить измерение скорости распространения ультразвуковой

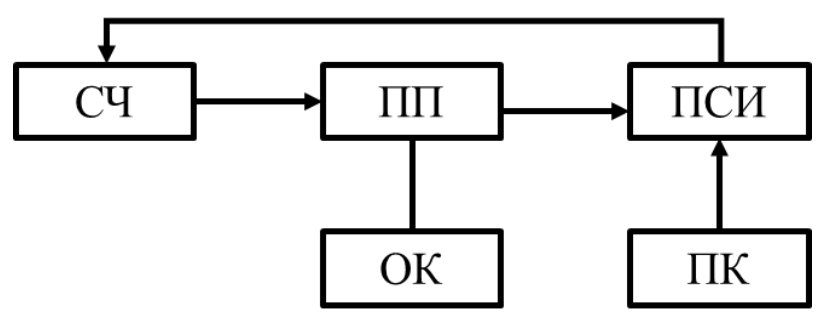

Рис. 3. Структурная схема лабораторной установки для измерения времени прохождения $t$ и геометрических размеров базы прозвучивания $h$ ультразвуковой волны в порошковых материалах ${ }^{\wedge}$ СЧ - синтезатор сигналов; ОК - объект

контроля; ПП - блок фиксации ультразвуковых преобразователей на поверхности ОК; ПСИ - плата сбора информации; ПК - персональный компьютер 
волны с погрешностью менее 1\%. Уменьшение погрешности достигается за счёт автоматизации процесса измерения акустических и геометрических параметров ОК, а также использования методов статистической обработки полученных экспериментальных данных.

Определение модуля упругости первого рода $E$ исследуемого материала заложено в алгоритм работы системы и производится автоматически по команде оператора. Для его вычисления использовали формулу (2).

$$
E=\frac{C_{l}^{2} \cdot \rho \cdot(1+v) \cdot(1-2 \cdot v)}{(1-v)},
$$

где $C_{l}$ - скорость распространения продольных акустических волн в материале, м/с; $\rho$ - плотность материала, кг $/ \mathrm{M}^{3} ; v-$ коэффициент Пуассона.

На рис. 4 приведены усреднённые результаты определения скорости распространения ультразвуковой волны в образцах, изготовленных из $\mathrm{AlN}$, по технологии описанной выше. Для каждого образца измерение его акустических параметров проводилось 50 раз.

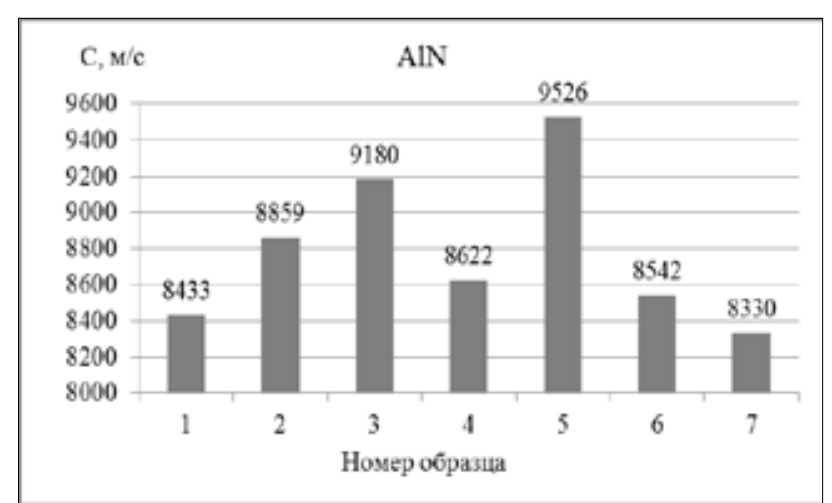

Рис. 4. Скорость распространения ультразвуковой волны в образцах AIN

В табл. 2 приведены рассчитанные по экспериментальным данным значения удельной плотности $\rho$, модуля упругости $E$ (ГПа) и коэф- фициент пропорциональности $K$ образцов. Коэффициент пропорциональности $K$ показывает отношение величин удельной плотности к модулю упругости.

Из рисунка 4 видно, что скорость распространения УЗ волны в исследуемых образцах изменяется в пределах $10 \%$, что значительно превышает суммарную погрешность измерения для данного лабораторного стенда. Из этого можно сделать вывод, что и разброс прочностных характеристик между образами будет лежать в пределах $10 \%$. В тоже время изменение скорости распространения ультразвуковой волны в объёме отдельно взятого образца не превышает $1 \%$, что соизмеримо с суммарной погрешностью используемого измерительного оборудования. Поэтому можно сделать вывод о стабильности распределения акустических, а значит и прочностных, характеристик в объёме отдельно взятого образца при их изготовлении по описанной технологии.

Анализ данных, приведённых в таблицы 1 и на рисунке 4 , показал, что изменение скорости распространения УЗВ и модуля упругости первого рода в образцах коррелирует с изменением удельной плотности. Из этого можно сделать выводы, что, несмотря на использование одних и тех же параметров, при технологии изготовления данных порошковых материалов пористость в полученных образцах варьируется. В тоже время коэффициент пропорциональности $K$ из таблицы 1 сохраняет близкие значения на образцах разной плотности.

Разброс акустических и прочностных свойств исследуемых порошковых материалов на основе нитрида алюминия можно объяснить разбросом физических свойств исходных порошковых компонентов, необеспечением стабильности технологических параметров при изготовлении материалов, а также неравномерностью температуры спекания в объёме образца.

Таблица 1

Физико-механические параметры нитрида алюминия

\begin{tabular}{|c|c|c|c|}
\hline \multirow{2}{*}{ № образца } & $\begin{array}{c}\text { Удельная плотность, } \\
\boldsymbol{\rho}, \frac{\kappa 2}{M^{3}}\end{array}$ & $\begin{array}{c}\text { Модуль упругости Е, } \\
\text { ГПа }\end{array}$ & $\begin{array}{c}\text { Коэффициент пропорциональности, } \\
K=\frac{\rho}{E}, \frac{\kappa 2}{M^{3}} \cdot \text { ГПа }\end{array}$ \\
\hline 1 & 2883 & 174 & 16,6 \\
\hline 2 & 2891 & 192 & 15,1 \\
\hline 3 & 3109 & 222 & 14 \\
\hline 4 & 3004 & 189 & 15,9 \\
\hline 5 & 3199 & 246 & 16,2 \\
\hline 6 & 2883 & 178 & 16,9 \\
\hline 7 & 2955 & 174 & \\
\hline
\end{tabular}


Выводы. Результаты работы показали, что по результатам акустических измерений можно судить о проведении интегральной оценки однородности распределения прочностных характеристик в порошковых материалах, изготовленных на основе нитрида алюминия, как в объёме отдельно взятого образца, так и об их повторяемости в пределах партии образцов. По результатам экспериментальных исследований установлено, что в партии образцов, изготовленных по одной и той же технологии, присутствует разброс физикомеханических характеристик (плотность, модуль упругости) в пределах $10 \%$ за счёт разброса значений сырья, технологических параметров, условий прессования и разности температуры спекания, в то время как в пределах одного образца распределение данных характеристик стабильно.

Таким образом, предложенная методика может быть использована для неразрушающего контроля материалов на основе нитрида алюминия.

\section{Список литературы:}

1. Костенко В.И., Серегин В.С, Грошкова Л.А., Василевич А.И. Перспективы использования высокотеплопроводной керамики из нитрида алюминия в космическом приборостроении. Boпpocbl миниатюризации в современном космическом приборостроении. Труды семинара ИКИ РАН. Таруса, 2004. C. $250-256$.

2. Флоренцев С.Н. Силовая электроника начала тысячелетия. Электротехника. 2003. № 6. С. 3-9.

3. Лоренц Л. Состояние и направление дальнейшего развития в сфере разработки, производства и применения полупроводниковых приборов. Электротехника. 2002. № 3. С. 2-16.

4. Belyanin A.F., Bouilov L.L., Zhirnov V.V., Kamenev A.I., Kovalskij K.A., Spitsyn B.V. Application of aluminum nitride films for electronic devices. Diamond and Related Materials. 1999. Vol. 8. No (2-5). P. 369-372.

5. Бершадская М.Д., Аветиков В.Г. и др. Нитрид алюминия - новый высокотеплопроводный диэлектрик. Электронная техника. Серия 6. Материальы. 1984. Вып. 6 (191). С. 54-57.

6. Белянин А.Ф., Самойлович М.И., Житковский В.Д. Ударостойкие защитные плёночные покрытия на основе AlN в электронной технике. Технология и конструирование в электронной аппаратуре. 2005. № 5. C. 35-41.

7. Бабичев А.П., Бабушкина Н.А. и др. Физические величины: Справочник / Под. ред. И.С. Григорьева, Е.3. Мейлихова. Москва : Энергоатомиздат, 1991. 1232 с.

8. Никитушкин И.В., Анненков Ю.М. Теплопроводная нанокерамика из нитрида алюминия и сопутствующие материалы, полученные методами высокоинтенсивных технологий. Матер. рос. молодежн. науч.-техн. конф. «Энергетика, электромеханика и энергоэффективные технологии глазами молодёжи», Томск, 2013. С. 58-61.

9. Арзамасов В.Б., Волчко А.Н. Материаловедение и технология конструкционных материалов : учебник для студентов высших учебных заведений. Москва : Академия, 2009. 448 с.

10. Неразрушающий контроль и диагностика: Справочник. / под ред. В.В. Клюева. Москва : Машиностроение, 2003. 656 с.

11. Безымянный Ю.Г., Богдан Г.А., Евко И.Г., Иванюк Н.А., Козирацкий Е.А. Контроль неоднородности свойств порошковых материалов по результатам акустических измерений. Вестник наи. техн. ун-та «ХПИ»: сб. научн. тр. Темат. вып.: Электроэнергетика и преобразовательная техника. Харьков : НТУ «ХПИ». 2011. № 19. С. 204-211.

12. Галаган Р.М. Теоретичні основи ультразвукового неруйнівного контролю : підручник для здобувачів ступеня бакалавра за освітньою програмою «Комп’ютерно-інтегровані технології та системи неруйнівного контролю і діагностики» спеціальності «Автоматизація та комп’ютерно-інтегровані технології». КПІ ім. Ігоря Сікорського. Електронні текстові дані. Київ : КПІ ім. Ігоря Сікорського, 2019. 263 с.

13. Богдан Г.А., Баженов В.Г., Кравченко М.В. Цифровая система измерения фазовых сдвигов радиоимпульсных сигналов. Международный научно-исследовательский журнал. Екатеринбург, 2016. № 4(46). Часть 2. С. 36-39.

\section{КОНТРОЛЬ ОДНОРІДНОСТІ РОЗПОДІЛУ ХАРАКТЕРИСТИК МІЦНОСТІ В МАТЕРІАЛАХ 3 НІТРИДУ АЛЮМІНІЮ ЗА РЕЗУЛЬТАТАМИ АКУСТИЧНИХ ВИМІРЮВАНЬ}

У статті розглянуті питання проведення інтегральної оцінки однорідності розподілу міинісних характеристик порошкових матеріалів, які виготовлені на основі нітриду алюмінію, за результатами акустичних вимірювань. Для визначення акустичних властивостей матеріалу був реалізований ультразвуковий метод проходження. Основним інформаційним параметром для досліджень була використана швидкість проходження ультразвукової хвилі в об 'єкті контролю. За результатами експериментальних досліджень встановлено, щьо є розбіжність фізико-механічних характеристик (густина, 
модуля пружності) у межах 10\%. Такий розкид виник за рахунок варіації фізико-механічних характеристик за рахунок розкиду значень сировини, технологічних параметрів, умов пресування та відмінності температур спікання.

Ключові слова: ультразвук, неруйнівний контроль, швидкість поширення, порошкові матеріали, нітрид алюмінію, технологія виготовлення.

\section{CONTROL OF HOMOGENEITY OF DISTRIBUTION OF DURABILITY DESCRIPTIONS IN MATERIALS FROM NITRIDE OF ALUMINIUM ON RESULTS OF ACOUSTIC MEASURING}

In the article the questions of realization of integral estimation of homogeneity of distribution of durability descriptions are considered in the powder-like materials made on basis nitride of aluminum, on results the acoustic measuring. For determination of acoustic parameters of material, the ultrasonic method of passing was realized. As basic informative parameters for researches speed of passing of ultrasonic wave was used in the object of control. It is set on results experimental researches, that in standards there is variation of physical and mechanical descriptions (closeness, module of resiliency) within the limits of $10 \%$. Such a due to variation of values of raw material, technological parameters, terms of pressing and difference of temperature of sintering.

Key words: ultrasound, non-destructive control, speed of distribution, powder-like materials, nitride of aluminum, technology of making. 